Case Report

\title{
Pott's Disease in a 2-Year-Old Child Treated by Decompression and Anterior-Posterior Instrumented Fusion
}

\author{
Mehmet Nuri Erdem, ${ }^{1}$ Cem Sever, ${ }^{2}$ Mehmet Fatih Korkmaz, ${ }^{3}$ Sinan Karaca, ${ }^{4}$ \\ Ferit Kirac, ${ }^{5}$ and Mehmet Tezer ${ }^{1}$ \\ ${ }^{1}$ Department of Orthopaedic Surgery, International Kolan Hospital, Darülaceza Caddesi No. 14 Okmeydanı, 34360 Istanbul, Turkey \\ ${ }^{2}$ Department of Orthopaedic Surgery, School of Medicine, Mevlana University, Dökümcü Sk No. 7, Meram Merkez, \\ 42090 Konya, Turkey \\ ${ }^{3}$ Department of Orthopaedic Surgery, School of Medicine, Inonu University, Malatya Merkez, 44000 Malatya, Turkey \\ ${ }^{4}$ Department of Orthopaedic Surgery, Fatih Sultan Mehmet Training and Research Hospital Atasehir, 34758 Istanbul, Turkey \\ ${ }^{5}$ Department of Orthopaedic Surgery, Diyarbakır Training and Research Hospital, Ückuyular Mevki TOKI karşısl, \\ 21010 Diyarbakır, Turkey
}

Correspondence should be addressed to Sinan Karaca; mdsnn@hotmail.com

Received 21 December 2013; Accepted 11 February 2014; Published 11 March 2014

Academic Editors: Y. Kasai and C. W. Muller

Copyright (C) 2014 Mehmet Nuri Erdem et al. This is an open access article distributed under the Creative Commons Attribution License, which permits unrestricted use, distribution, and reproduction in any medium, provided the original work is properly cited.

Introduction. Paraplegia and kyphotic deformity are two major disease-related problems of spinal tuberculosis, especially in the early age disease. In this study a 2 -year-old boy who underwent surgical decompression, correction, and $360^{\circ}$ instrumented fusion via simultaneous anterior-posterior technique for Pott's disease was reported. Case Report. A 2-year-and-9-month-old boy presented with severe back pain and paraparesis of one-month duration. Thoracic magnetic resonance imaging demonstrated destruction with a large paraspinal abscess involving T5-T6-T7 levels, compressing the spinal cord. The paraspinal abscess drained and threelevel corpectomy was performed at T5-6-7 with transthoracic approach. Anterior instrumentation and fusion was performed with structural 1 autogenous fibula and rib graft using screw-rod system. In prone position pedicle screws were inserted at T4 and T8 levels and rods were placed. Six months after surgery, there was no weakness or paraparesis and no correction loss at the end of follow-up period. Discussion. In cases of vertebral osteomyelitis with severe anterior column destruction in the very early child ages the use of anterior structural grafts and instrumentation in combination with posterior instrumentation is safe and effective in maintenance of the correction achieved and allows efficient stabilization and early mobilization.

\section{Introduction}

Spinal tuberculosis, the most common pattern of extra pulmonary tuberculosis, also has increased rapidly around the world in recent years, especially in the undeveloped and developing countries [1]. Paraplegia and kyphotic deformity development are two major disease-related problems. Medical and surgical decompression (antituberculous treatment and debridement) and early reconstruction of spinal stability plays an important role in the surgical management of spinal tuberculosis $[2,3]$. The reported techniques of surgical treatment range from anterior debridement and interbody fusion $[4,5]$ and debridement and internal fixation from the posterior approach [6] to combined single-stage or twostage posterior instrumentation with anterior debridement and bone grafting [7-14]. Recently decompression, fusion, and instrumentation by simultaneous posterior-anteriorposterior surgery are recommended for effective kyphosis correction and early ambulation [15]. In this study a 2 -yearold boy who suffered from severe paraparesia and back pain was reported. The aim of this case report is to verify the importance of early reconstruction of spinal stability and the technique of $360^{\circ}$ fusion via simultaneous anterior-posterior in a 2-year-old patient. 


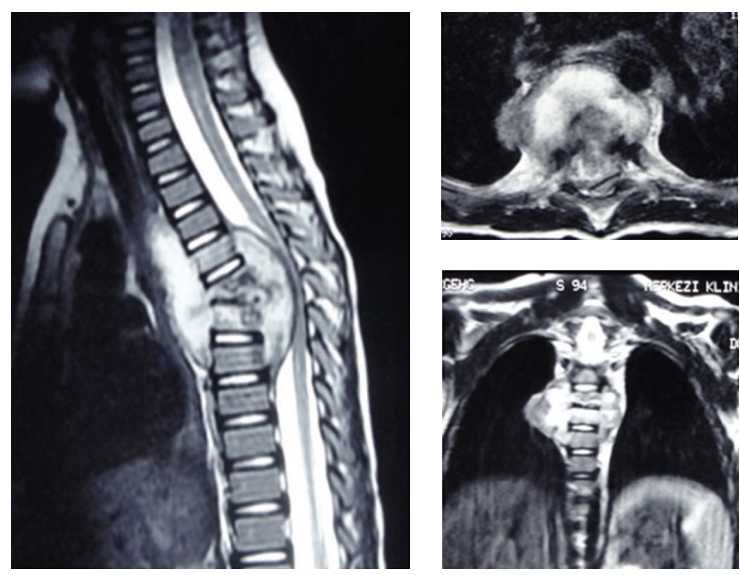

FIGURE 1: Preoperative MR images demonstrated a large paraspinal abscess.

\section{Case Presentation}

A 2-year-and-9-month-old boy was admitted to our department with back pain that had developed over a 1-month period. Neurological examination revealed a paraparesis, which was evaluated as grade $\mathrm{C}$ according to Frankel Scoring System. Roentgenograms of chest and thoracic spine showed destruction at the T5-T6-T7 levels and the local kyphosis angle was $37^{\circ}$ at this level. Thoracic magnetic resonance imaging (MRI) demonstrated a large paraspinal abscess involving these three levels, extending to the spinal canal and compressing the spinal cord (Figure 1). There was no other infection focus in physical examination, radiological, hematological, and biochemical tests. Emerge surgical procedure was performed after preoperative evaluation was completed.

The surgery was performed under general anesthesia with the transthoracic approach after removing the fifth rib in right lateral decubit position. After exposure, the paraspinal abscess drained spontaneously. Because of the bone destruction and cord compression, three-level corpectomy was performed at T5-6-7. Sequestered bone fragments of affected vertebrae were removed through corpectomy. Decompression was carried out until duramater was visible through anterior approach, so all affected vertebrae were extracted. The deformity was flexible; the reduction of kyphosis performed until physiological angels and anterior fusion was performed with structural 1 autogenous fibula and 1 autogenous rib graft. Periost of the fibula was prevented and closed anatomically after resection. Anterior instrumentation with one screw to each vertebra at T4 and T8 was performed to increase the primer stability (Figure 2). The system locked, thorax drainage system applied, and thoracotomy closed. The patient was positioned prone. Bilateral polyaxial pedicle screws were inserted at T4 and T8 levels and rods were placed for permanent fixation (Figure 3). Pediatric spinal screw systems were preferred for the immature pedicles (Tasarım med, Istanbul, Turkey).

Microbiological examination of tissue and abscess samples obtained during operation was Mycobacterium Tuberculosis. No complication of bleeding persisted and the drainage

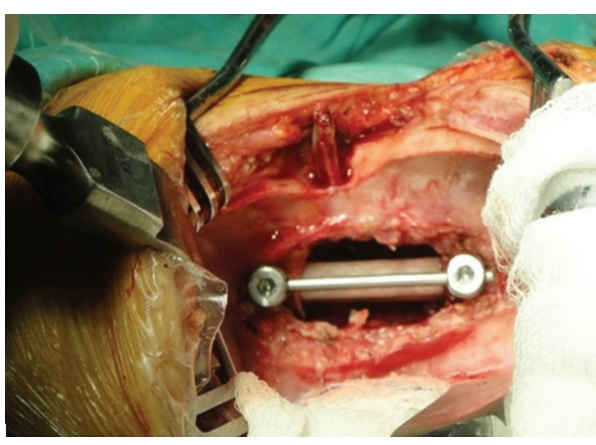

FIGURE 2: Anterior instrumentation with structural autogenous fibula and autogenous rib graft.
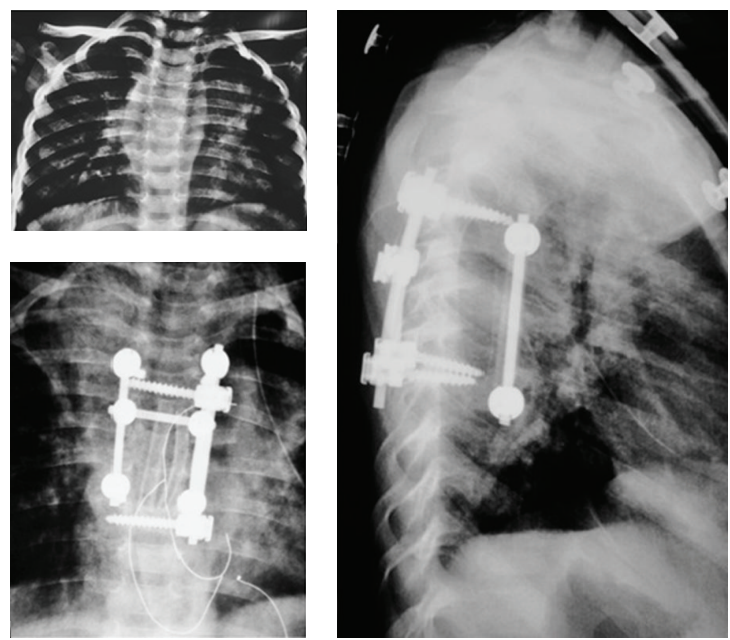

FIGURE 3: Preoperative and postoperative plain roentgenograms.

tube was taken after 72 hours. One week after surgery, the patient could sit on the bed or walk around under the effective support of thoracolumbosacral orthoses, and this orthoses support was maintained for 3 months. The patient received antituberculosis chemotherapy for 9 months $(3$ months of INH-rifampicin-pyrazinamide-streptomycin therapy, followed by 6-month INH-rifampicin-pyrazinamide therapy). 6 weeks after surgery, neurological status of the patient was Frankel E and there was no weakness or paresthesia which was presented before the surgery. Kyphosis angle showed a correction of a $4^{\circ}(89.2 \%)$ in the postoperative period and there was no correction loss at the end of follow-up period.

\section{Discussion}

Tuberculosis of the spine is an unstable lesion that tends to progress until having bony fusion at the spine. Bone fusion of the vertebrae is thought to be the most reliable evidence of healing of spinal tuberculosis [16]. To achieve this aim, many treatment methods have been developed, chemotherapy alone and chemotherapy combined with surgical management. Indications for surgery in spinal tuberculosis are reported to include the presence of a large paraspinal 
abscess, the presence of severe bone destruction and kyphotic deformity, neurologic deficit with spinal cord compression, and lack of response to conservative treatment [17].

The aims of spinal tuberculosis treatment are to eradicate the disease, to prevent the development of paraplegia and kyphotic deformity, to manage the existing deformity and neurological deficit, to allow early ambulation, and to return the patient back to daily life $[1,18-21]$.

There are many options for surgical treatment of spinal tuberculosis including anterior debridement and arthrodesis $[22,23]$, plates and screws $[3,5,24]$, titanium mesh cages $[10$, 25 ], and posterior instrumentation combined with anterior decompression in single or consecutive two stages $[15,26-$ 30]. Anterior debridement and fusion using autogenous bone grafts, as a classical method, allow effective debridement and rapid bony union with the grafts and prevent progressive collapse and kyphosis [22, 31-33]. However, it has been reported that such successful outcomes are not observed regarding progressive collapse and kyphosis, particularly in the case of two or more levels of involvement, risks of graft insufficiency, and increased kyphotic deformity $[1,5,18,19,34-36]$. The reported drawbacks of anterior radical surgery suggest that anterior arthrodesis combined with anterior or posterior instrumentation may be useful to maintain the correction achieved $[5,8,24,29,35$, 37]. In our experience $360^{\circ}$ spinal fusion method using posterior-anterior-posterior titanium mesh cage and posterior instrumentation in tuberculosis spondylitis affecting two or more levels accompanied by moderate or severe kyphosis that requires surgery achieves kyphosis correction comparable to normal anatomic degrees, allows efficient stabilization and early mobilization, and is effective in maintenance of the correction achieved [15]. In this case we prefer to start with anterior debridement and instrumentation because of the flexibility of the deformity due to his age.

In the literature, there are few reports about surgical treatment of spinal tuberculosis in early child ages. To our knowledge this is the first report that shows the surgical treatment which is applied with anterior debridement, anterior instrumentation with structural autogenously fibula, and rib graft and posterior transpedicular instrumentation in early childhood.

In conclusion, in cases of vertebral osteomyelitis with severe anterior column destruction in the early child ages the use of anterior structural grafts and instrumentation in combination with posterior instrumentation is safe and effective in maintenance of the correction achieved and allows efficient stabilization and early mobilization. Further follow-up and series with more account of patients are necessary to confirm these early results.

\section{Conflict of Interests}

The authors declare that there is no conflict of interests regarding the publication of this paper.

\section{References}

[1] M.-S. Moon, "Spine update tuberculosis of the spine: controversies and a new challenge," Spine, vol. 22, no. 15, pp. 1791-1797, 1997.

[2] T.-C. Lee, K. Lu, L.-C. Yang, H.-Y. Huang, and C.-L. Liang, "Transpedicular instrumentation as an adjunct in the treatment of thoracolumbar and lumbar spine tuberculosis with early stage bone destruction," Journal of Neurosurgery, vol. 91, no. 2, pp. 163-169, 1999.

[3] C. Yilmaz, H. Y. Selek, I. Gürkan, B. Erdemli, and Z. Korkusuz, "Anterior instrumentation for the treatment of spinal tuberculosis," The Journal of Bone and Joint Surgery. American, vol. 81, no. 9, pp. 1261-1267, 1999.

[4] H. Matsui, N. Hirano, and Y. Sakaguchi, "Vertebral osteomyelitis: an analysis of 38 surgically treated cases," European Spine Journal, vol. 7, no. 1, pp. 50-54, 1998.

[5] I. T. Benli, E. Acaroğlu, S. Akalın, M. Kiş, E. Duman, and A. Un, "Anterior radical debridement and anterior instrumentation in tuberculosis spondylitis," European Spine Journal, vol. 12, no. 2, pp. 224-234, 2003.

[6] S. A. Rath, U. Neff, O. Schneider, and H.-P. Richter, "Neurosurgical management of thoracic and lumbar vertebral osteomyelitis and discitis in adults: a review of 43 consecutive surgically treated patients," Neurosurgery, vol. 38, no. 5, pp. 926-933, 1996.

[7] P. M. Arnold, P. N. Baek, R. J. Bernardi, E. A. Luck, and S. J. Larson, "Surgical management of nontuberculous thoracic and lumbar vertebral osteomyelitis: report of 33 cases," Surgical Neurology, vol. 47, no. 6, pp. 551-561, 1997.

[8] A. A. Faraj and J. K. Webb, "Spinal instrumentation for primary pyogenic infection report of 31 patients," Acta Orthopaedica Belgica, vol. 66, no. 3, pp. 242-247, 2000.

[9] A. G. Hadjipavlou, J. T. Mader, J. T. Necessary, and A. J. Muffoletto, "Hematogenous pyogenic spinal infections and their surgical management," Spine, vol. 25, no. 13, pp. 1668-1679, 2000.

[10] H. T. Hee, M. E. Majd, R. T. Holt, and D. Pienkowski, "Better treatment of vertebral osteomyelitis using posterior stabilization and titanium mesh cages," Journal of Spinal Disorders, vol. 15, no. 2, pp. 149-156, 2002.

[11] A. Krödel, A. Krüger, K. Lohscheidt, M. Pfahler, and H. J. Refior, "Anterior debridement, fusion, and extrafocal stabilization in the treatment of osteomyelitis of the spine," Journal of Spinal Disorders, vol. 12, no. 1, pp. 17-26, 1999.

[12] M. Oga, T. Arizono, M. Takasita, and Y. Sugioka, "Evaluation of the risk of instrumentation as a foreign body in spinal tuberculosis: clinical and biologic study," Spine, vol. 18, no. 13, pp. 1890-1894, 1993.

[13] G. J. Przybylski and A. D. Sharan, "Single-stage autogenous bone grafting and internal fixation in the surgical management of pyogenic discitis and vertebral osteomyelitis," Journal of Neurosurgery, vol. 94, no. 1, pp. 1-7, 2001.

[14] G. D. Sundararaj, S. Behera, V. Ravi, K. Venkatesh, V. M. Cherian, and V. Lee, "Role of posterior stabilisation in the management of tuberculosis of the dorsal and lumbar spine," The Journal of Bone and Joint Surgery. British, vol. 85, no. 1, pp. 100-106, 2003.

[15] E. Erturer, M. Tezer, M. Aydogan, C. Mirzanli, and I. Ozturk, "The results of simultaneous posterior-anterior-posterior surgery in multilevel tuberculosis spondylitis associated with severe kyphosis," European Spine Journal, vol. 19, no. 12, pp. 2209-2215, 2010. 
[16] O. Boachie-Adjei and R. G. Squillante, "Tuberculosis of the spine," Orthopedic Clinics of North America, vol. 27, no. 1, pp. 95-103, 1996.

[17] A. R. Rezai, M. Lee, P. R. Cooper et al., "Modern management of spinal tuberculosis," Neurosurgery, vol. 36, no. 1, pp. 87-98, 1995.

[18] A. Hamzaoglu, "Granulomatous infection of the spine," in State of the Art Reviews-Spinal Infections, Y. Floman, Ed., pp. 45-78, Hanley and Belfus, Philadelphia, Pa, USA, 1999.

[19] A. S. Hilibrand, L. G. Quartararo, and M. R. J. Moulton, "Spinal infections," in Orthopaedic Knowledge Uptake 7, K. J. Koval, Ed., pp. 661-672, American Academy of Orthopaedic Surgeons, 2003.

[20] J.-P. Janssens and R. de Haller, "Spinal tuberculosis in a developed country. A review of 26 cases with special emphasis on abscesses and neurologic complications," Clinical Orthopaedics and Related Research, no. 257, pp. 67-75, 1990.

[21] K. D. K. Luk, "Tuberculosis of the spine in the new millennium," European Spine Journal, vol. 8, no. 5, pp. 338-345, 1999.

[22] "A 10-year assessment of a controlled trial comparing debridement and anterior spinal fusion in the management of tuberculosis of the spine in patients on standard chemotherapy in Hong Kong. Eighth Report of the Medical Research Council Working Party on Tuberculosis of the Spine," The Journal of Bone and Joint Surgery. British, vol. 64, no. 4, pp. 393-398, 1982.

[23] "A 15-year assessment of controlled trials of the management of tuberculosis of the spine in Korea and Hong Kong. Thirteenth Report of the Medical Research Council Working Party on Tuberculosis of the Spine," The Journal of Bone and Joint Surgery. British, vol. 80, no. 3, pp. 456-462, 1998.

[24] D. Jin, D. Qu, J. Chen, and H. Zhang, "One-stage anterior interbody autografting and instrumentation in primary surgical management of thoracolumbar spinal tuberculosis," European Spine Journal, vol. 13, no. 2, pp. 114-121, 2004.

[25] U. Liljenqvist, T. Lerner, V. Bullmann, L. Hackenberg, H. Halm, and W. Winkelmann, "Titanium cages in the surgical treatment of severe vertebral osteomyelitis," European Spine Journal, vol. 12, no. 6, pp. 606-612, 2003.

[26] W.-J. Chen, C.-C. Wu, C.-H. Jung, L.-H. Chen, C.-C. Niu, and P.-L. Lai, "Combined anterior and posterior surgeries in the treatment of spinal tuberculous spondylitis," Clinical Orthopaedics and Related Research, no. 398, pp. 50-59, 2002.

[27] M.-S. Moon, Y.-K. Woo, K.-S. Lee, K.-Y. Ha, S.-S. Kim, and D.-H. Sun, "Posterior instrumentation and anterior interbody fusion for tuberculous kyphosis of dorsal and lumbar spines," Spine, vol. 20, no. 17, pp. 1910-1916, 1995.

[28] O. Safran, N. Rand, L. Kaplan, S. Sagiv, and Y. Floman, "Sequential or simultaneous, same-day anterior decompression and posterior stabilization in the management of vertebral osteomyelitis of the lumbar spine," Spine, vol. 23, no. 17, pp. 1885-1890, 1998.

[29] C. Klöckner and R. Valencia, "Sagittal alignment after anterior debridement and fusion with or without additional posterior instrumentation in the treatment of pyogenic and tuberculous spondylodiscitis," Spine, vol. 28, no. 10, pp. 1036-1042, 2003.

[30] V. J. Laheri, N. P. Badhe, and G. T. Dewnany, "Single stage decompression, anterior interbody fusion and posterior instrumentation for tuberculous kyphosis of the dorso-lumbar spine," Spinal Cord, vol. 39, no. 8, pp. 429-436, 2001.

[31] A. R. Hodgson and F. E. Stock, "Anterior spinal fusion: a preliminary communication on the radical treatment of Pott's disease and Pott's paraplegia," Clinical Orthopaedics and Related Research, no. 300, pp. 16-23, 1994.

[32] M.-S. Moon, Y.-W. Moon, J.-L. Moon, S.-S. Kim, and D.-H. Sun, "Conservative treatment of tuberculosis of the lumbar and lumbosacral spine," Clinical Orthopaedics and Related Research, no. 398, pp. 40-49, 2002.

[33] C. Wimmer, M. Ogon, W. Sterzinger, F. Landauer, and B. Stöckl, "Conservative treatment of tuberculous spondylitis: a longterm follow- up study," Journal of Spinal Disorders, vol. 10, no. 5, pp. 417-419, 1997.

[34] F. Denis, G. W. D. Armstrong, K. Searls, and L. Matta, "Acute thoracolumbar burst fractures in the absence of neurologic deficit. A comparison between operative and nonoperative treatment," Clinical Orthopaedics and Related Research, vol. 189, pp. 142-149, 1984.

[35] D.-J. Kim, Y.-H. Yun, S.-H. Moon, and K. D. Riew, "Posterior instrumentation using compressive laminar hooks and anterior interbody arthrodesis for the treatment of tuberculosis of the lower lumbar spine," Spine, vol. 29, no. 13, pp. 275-279, 2004.

[36] H. M. Özdemir, A. K. Us, and T. Öğün, "The role of anterior spinal instrumentation and allograft fibula for the treatment of Pott disease," Spine, vol. 28, no. 5, pp. 474-479, 2003.

[37] S. Fukuta, K. Miyamoto, T. Masuda et al., “Two-stage (posterior and anterior) surgical treatment using posterior spinal instrumentation for pyogenic and tuberculotic spondylitis," Spine, vol. 28, no. 15 , pp. 302-308, 2003. 


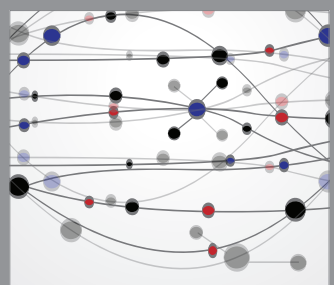

The Scientific World Journal
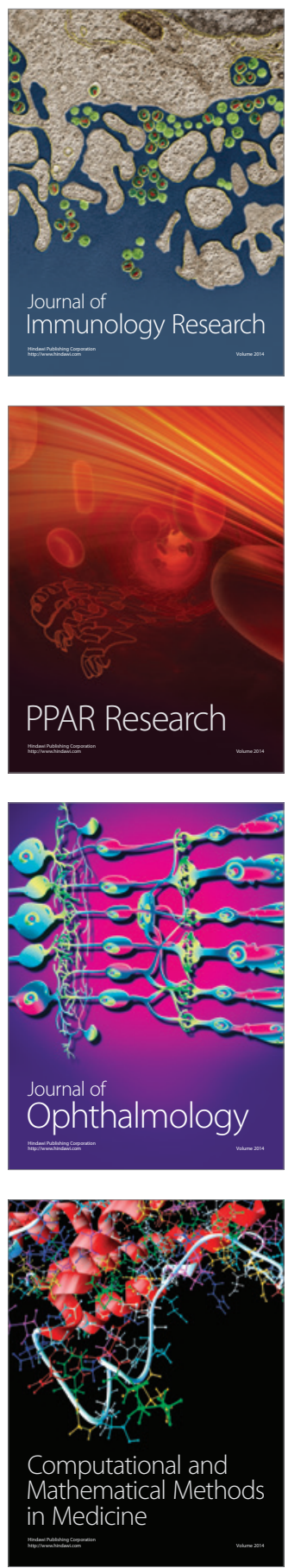

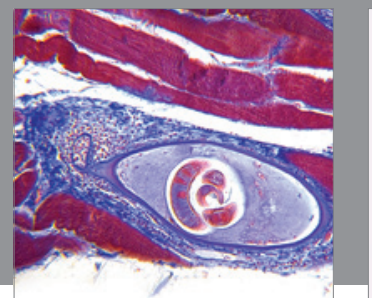

Gastroenterology

Research and Practice
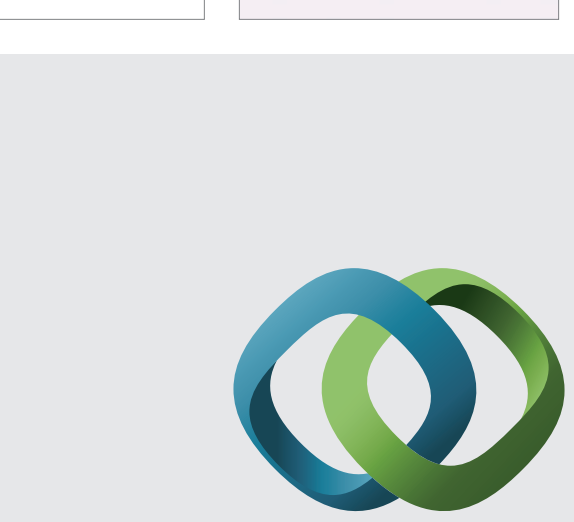

\section{Hindawi}

Submit your manuscripts at

http://www.hindawi.com
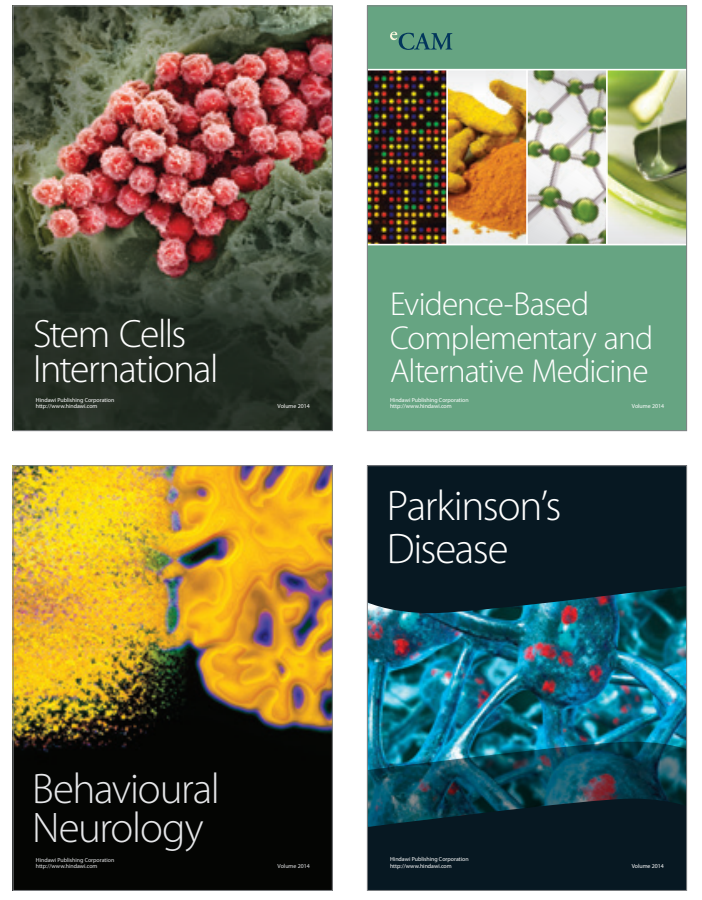
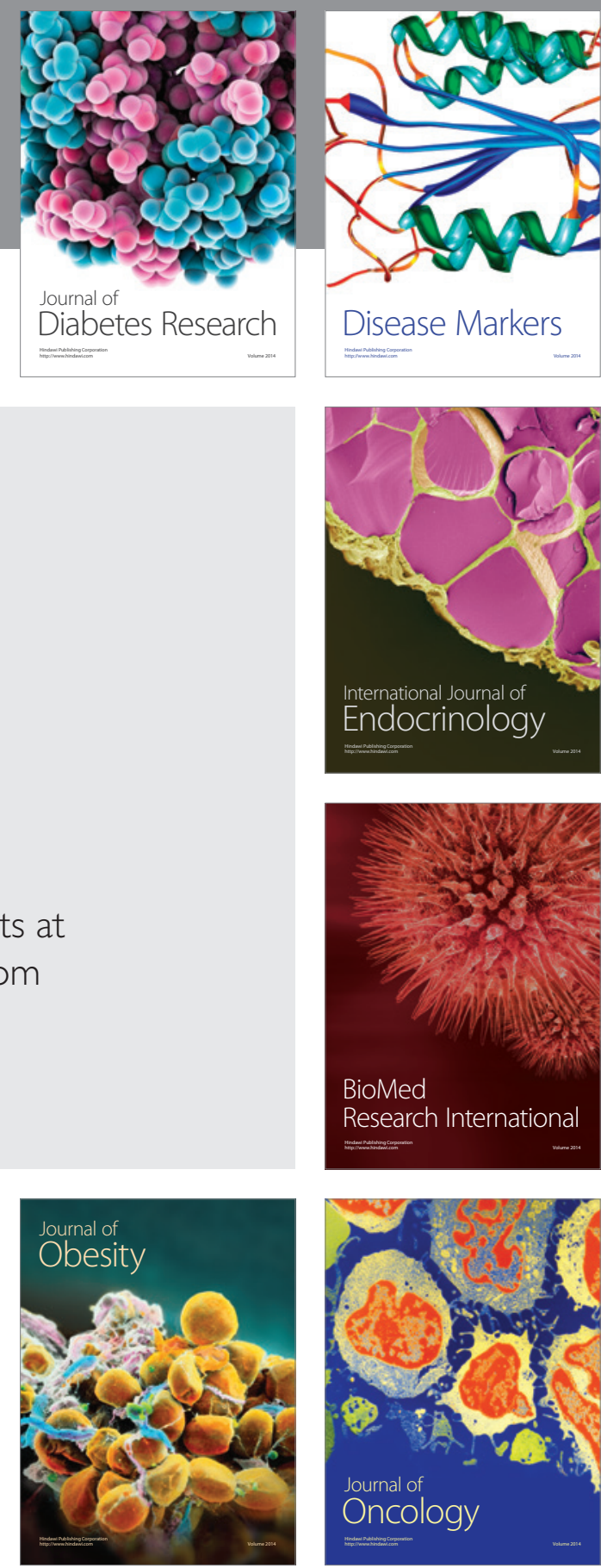

Disease Markers
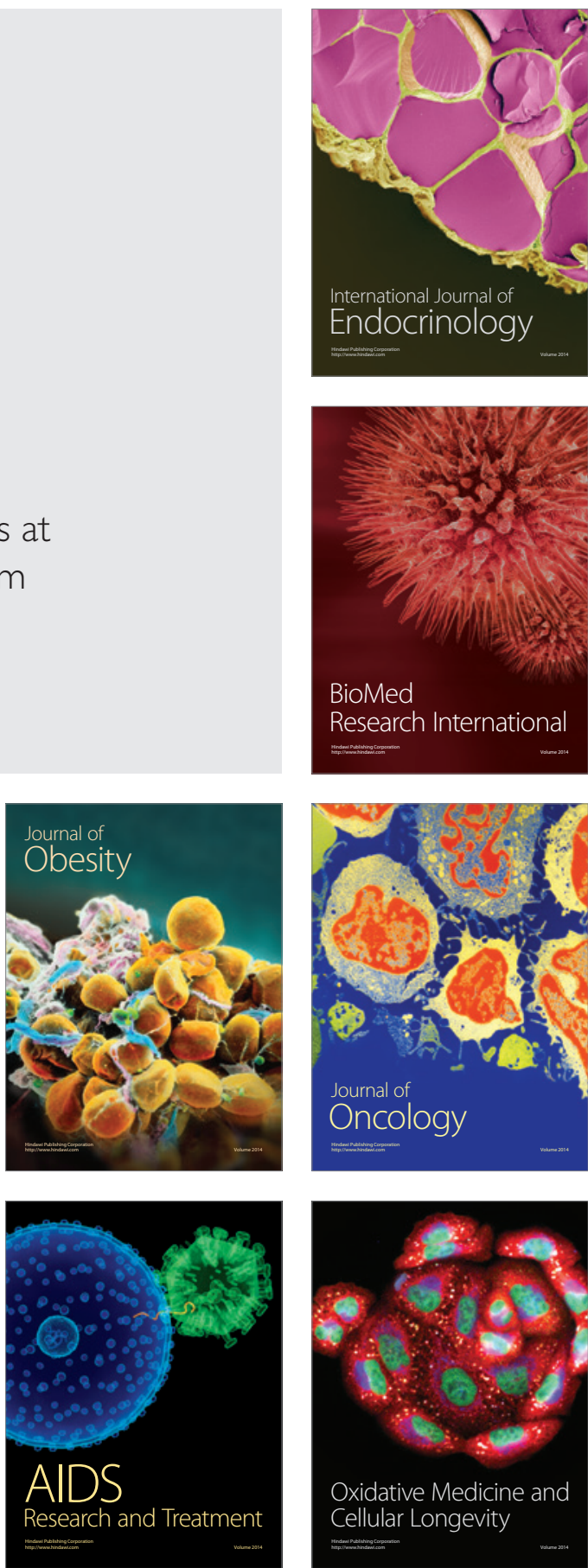